\title{
Study of Polymer Material Aging by Laser Mass Spectrometry, UV-Visible Spectroscopy, and Environmental Scanning Electron Microscopy
}

\author{
Junien Exposito, ${ }^{1,2}$ Claude Becker, ${ }^{2}$ David Ruch, ${ }^{2}$ and Frédéric Aubriet ${ }^{1}$ \\ ${ }^{1}$ Laboratoire de Spectrométrie de Masse et de Chimie Laser, Université Paul Verlaine-Metz, 1 Boulevard Arago, \\ 57078 Metz Technopole Cedex 3, France \\ ${ }^{2}$ Laboratoire de Technologies Industrielles, Centre de Recherche Public Henri Tudor, 66 rue du Luxembourg, \\ 4002 Esch/Alzette, Luxembourg \\ Correspondence should be addressed to David Ruch, david.ruch@tudor.lu
}

Received 18 July 2007; Accepted 16 October 2007

Recommended by Eli Ruckenstein

\begin{abstract}
Dyed natural rubber (NR) and styrene butadiene rubber (SBR), designed for outdoor applications, were exposed to an accelerated artificial aging in xenon light. The aging results in the deterioration of the exposed surface material properties. The ability of dyed polymers to withstand prolonged sunlight exposure without fading or undergoing any physical deterioration is largely determined not only by the photochemical characteristics of the absorbing dyestuff itself but also by the polymer structure and fillers. Results obtained by laser mass spectrometry, UV-visible spectroscopy, and environmental scanning electron microscopy indicate that dyed filled NR and SBR samples behave differently during the photo-oxidation. The fading of the dyed polymers was found to be promoted in the NR sample. This can be correlated with LDI-FTICRMS results, which show the absence of [M-H $]^{-}$orange pigment pseudomolecular ion and also its fragment ions after aging. This is confirmed by both EDX and UV/Vis spectroscopy. EDX analysis indicates a concentration of chlorine atoms, which can be considered as a marker of orange pigment or its degradation products, only at the surface of SBR flooring after aging. Reactivity of radicals formed during flooring aging has been studied and seems to greatly affect the behavior of such organic pigments.
\end{abstract}

Copyright (c) 2007 Junien Exposito et al. This is an open access article distributed under the Creative Commons Attribution License, which permits unrestricted use, distribution, and reproduction in any medium, provided the original work is properly cited.

\section{INTRODUCTION}

Under mechanical stress, temperature, moisture, radiations, and corrosive and aggressive environments, material performances decrease over the time. The alteration of use properties is named "aging" [1]. Understanding and predicting these degradation processes are really a great challenge. Consequently, the evaluation of material lifetime is very complex; this difficulty increases when composite materials are considered. In this paper, our attention is focused on a specific composite material: orange polymer-based flooring. This flooring is a mixture of different organic and inorganic fillers with an organic orange azoic pigment $\left(\mathrm{C}_{32} \mathrm{H}_{24} \mathrm{~N}_{8} \mathrm{O}_{2} \mathrm{Cl}_{2}\right)$ in a polymer matrix. The polymer matrix can correspond to different homopolymers or copolymers: natural rubber (NR), styrene butadiene rubber (SBR), or polybutadiene (PB).
Three different analytical techniques have been used to achieve a precise description of the material properties before and after aging. The laser desorption ionization coupled to Fourier transform ion cyclotron resonance mass spectrometry (LDI-FTICRMS) allows molecular information to be obtained [2]. Scanning electron microscopy (SEM) is used to investigate, after aging, the surface topology in secondary electron (SE) mode and to determine the distribution of atoms at the interface of aged/nonaged composite material in energy dispersive X-ray spectrometry (EDX). Moreover, UVvisible spectroscopy is used as a qualitative and quantitative approach to investigate the degradation of the material.

In this study, two composite floorings have been investigated before and after accelerated aging. The first one is associated to SBR polymer and darkened under UV/Vis 
<smiles>CC1=NN(c2ccccc2)C(=O)C1N=Nc1ccc(-c2ccc(/N=N/C3C(=O)N(c4ccccc4)N=C3C)c(Cl)c2)cc1Cl</smiles>

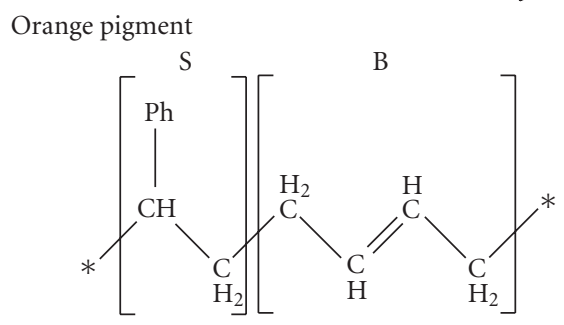

SBR (styrene butadiene rubber)

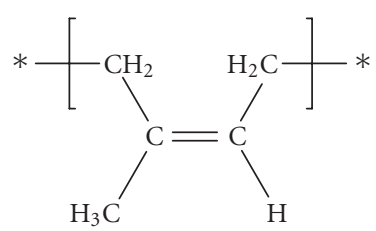

NR (natural rubber $=$ polyisoprene)

Scheme 1: Developed formula of orange pigment, natural rubber (NR), and styrene-butadiene rubber (SBR).

irradiation; the other one is based on NR polymer matrix and faded during aging.

\section{MATERIALS}

The investigated floorings are a mixture of different organic and inorganic fillers with an organic orange azoic pigment $\left(\mathrm{C}_{32} \mathrm{H}_{24} \mathrm{~N}_{8} \mathrm{O}_{2} \mathrm{Cl}_{2}\right)$ in a polymer matrix. Both compounds are constituted by $28.6 \%$ of polymer matrix, $8.7 \%$ of chemical products (stearic acid, coumarone resin, zinc and calcium oxides, polyethylene and microcristaline wax), 53.4\% of inorganic fillers (kaolin kick, kaolin GTY, silicium VN3, Argirec B24), $2.6 \%$ of titanium dioxide, $1.2 \%$ of orange pigment, and $1.4 \%$ of polymerization accelerators (CBS, sulfur, ZBEC).

The two investigated polymer matrices are natural rubber (NR) and styrene butadiene rubber (SBR). The structure of organic pigment is described in Scheme 1.

\section{METHODS}

\subsection{Artificial aging}

To accelerate degradation processes artificial aging with an Xe lamp is used [3]. The artificial simulated weathering was carried out in an Atlas Weatherometer Ci 5000 chamber equipped with a $6500 \mathrm{~W}$ borosilicate glass-filtered xenon arc source. The artificial aging program consists of a continuous irradiation of 168 hours. The intensity of radiation is auto adjusted to assure a global irradiation of $240 \mathrm{MJ} / \mathrm{m}^{2}$ for wavelengths in the 290 to $800 \mathrm{~nm}$ range.

\subsection{LDI-FTICR MS experiments}

All mass spectra are acquired in negative detection mode using an LDI-FTICR mass spectrometer (IonSpec, Lake Forest, Calif, USA) equipped with an actively shielded 9.4-tesla superconducting magnet (Cryomagnetics, Oak Ridge, Tenn,
USA) [4-6]. The external ion source ProMaldi card is used. Small pieces of samples are put on a specific sample holder prior to be introduced into the source region of the mass spectrometer. Ions were generated by LDI of the sample with an ORION air-cooled Nd:YAG laser system (New Wave Research Inc, Fremont, Calif, USA) working at the $355 \mathrm{~nm}$ wavelength (laser pulse duration 5 nanoseconds, outpout energy $4 \mathrm{~mJ}$ ). The ions resulting from 8 successive laser-sample interactions are stored in an RF-only hexapole before being transferred to the FTICR cell. After transfer, ions are trapped in the FTICR cell with a $0.2 \mathrm{~V}$ trapping potential. $\mathrm{m} / \mathrm{z} 100$ to 1500 ions are then excited by the application of an arbitrary excitation wave function on the excitation plates. The resulting image current is detected, amplified, digitized, apodized (Blackman), and Fourier-transformed to produce a mass spectrum. The signal is sampled during 2.097 seconds with 4096 Ko data points. The obtained mass accuracy is typically better than $0.75 \mathrm{ppm}$, and the mass resolution at $\mathrm{m} / \mathrm{z}$ 500 close to 400000 .

\subsection{SEM measurements}

SEM observations are carried out by using Quanta field emission gun environmental scanning electron microscope (SEM) from FEI (FEG-200) operating at $20.00 \mathrm{kV}$ and 0.70 mbar and 1.16 mbar. The origin of environmental SEM is directly linked to the high vacuum needed in electron microscopes, that introduce restrictions on the way that insulating specimens as polymer may be imaged without performing a preliminary conductive coating.

\subsection{UV/Vis spectroscopy measurements}

Experiments on solid state samples are performed using a Perklin Elmer UV/Vis spectrometer Lambda 14. Absorbance is recorded for the 200-900 $\mathrm{nm}$ wavelength range. 


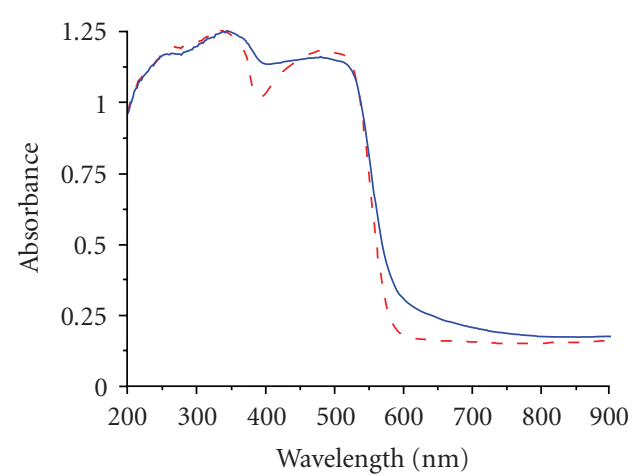

(a)

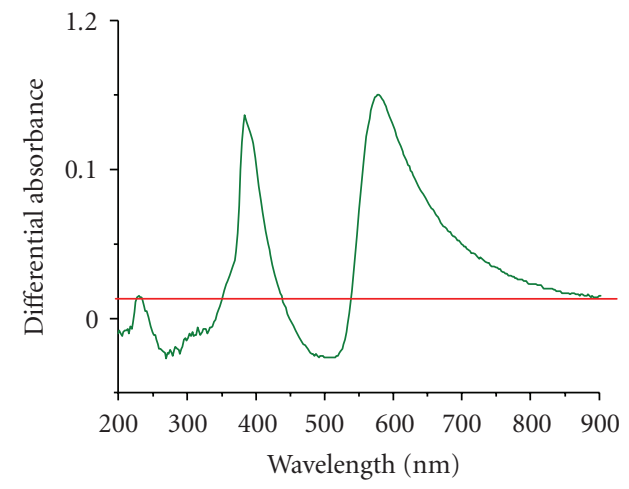

(c)

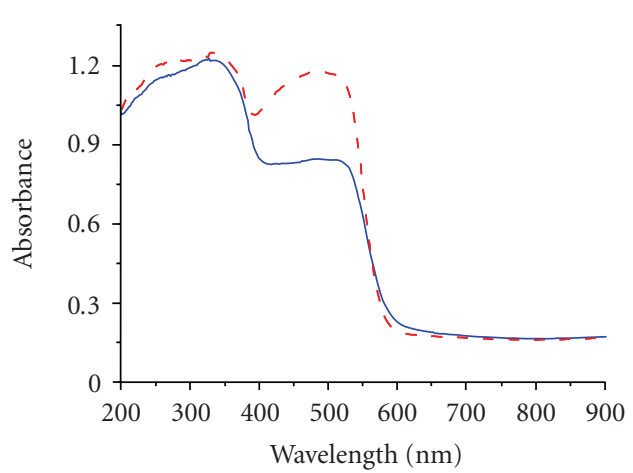

(b)

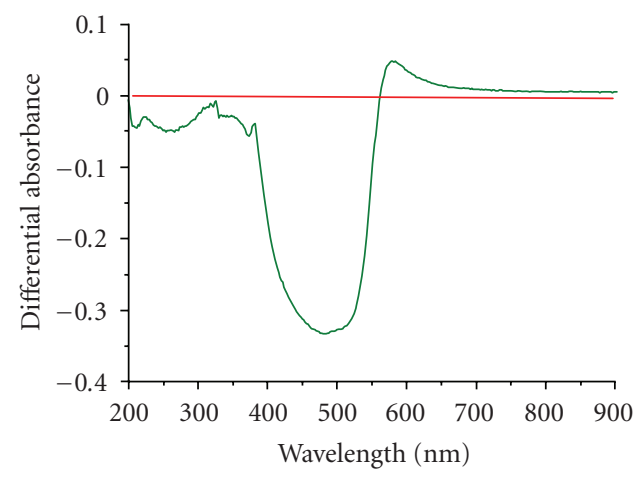

(d)

FIGURE 1: UV/Vis spectra of (a) SBR flooring and (b) NR flooring before (dashed line) and after aging (full line). Differential absorbance spectra for SBR (c) and NR (d) floorings (nonaged flooring is taken as the reference).

\section{RESULTS AND DISCUSSION}

\section{UV-visible spectroscopy}

The absorbance of NR, SBR, and orange pigment is first investigated. Both polymers present a significant absorption in the UV, whereas orange pigment strongly absorbs visible wavelength. The maximum of absorption is in the 200 $350 \mathrm{~nm}$ range for both polymers and in the $350-550 \mathrm{~nm}$ range for the orange pigment. Before aging, the absorption behavior of the orange-colored NR and SBR-based flooring could be considered as the additive behavior of polymer on the one hand and orange pigment on the other hand as it is reported in Figure 1. After aging, the behavior of both samples is modified. Absorption bands broaden for both samples. This is confirmed by differential UV/Vis spectroscopy reported in Figures 1(c) and 1(d). Small differential absorption peaks are systematically observed and could be considered as small pseudo- "red shift" after aging. This could be interpreted as an increasing number of conjugated unsaturations and/or incorporation of oxygen atoms in the hydrocarbon chains.

The UV/Vis spectrum of NR flooring reported in Figure 1 (b) also demonstrates a significant decrease of the absorption associated to the pigment after aging. This behavior is not observed for SBR-based flooring. This is confirmed by the visual aspect of both floorings: the color of NR-based flooring fades, whereas SBR-based flooring darkens.

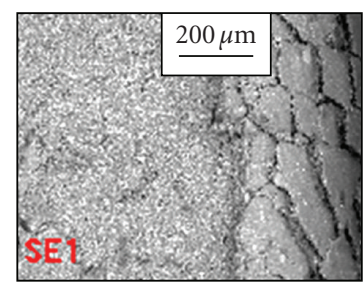

(a)

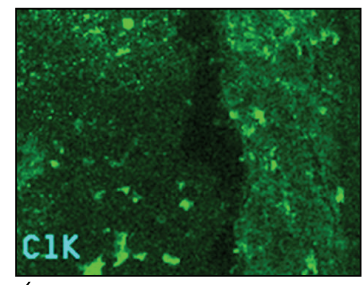

Bulk

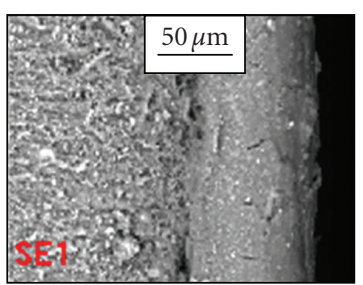

(b)

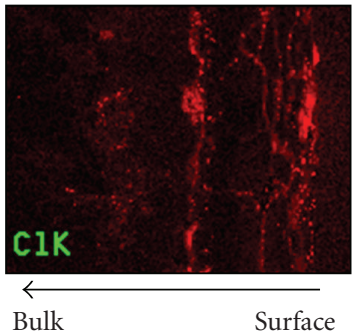

(d)
FIGURE 2: SEM analysis in secondary electron mode of aged (a) NRand (b) SBR-based floorings. K $\alpha$ chlorine mapping of aged (c) NR and (d) SBR-based floorings by EDX measurements.

\section{Surface analysis and EDX measurements}

The topology of the surface of both floorings has been investigated by SEM in secondary electron mode (Figures 2(a) 


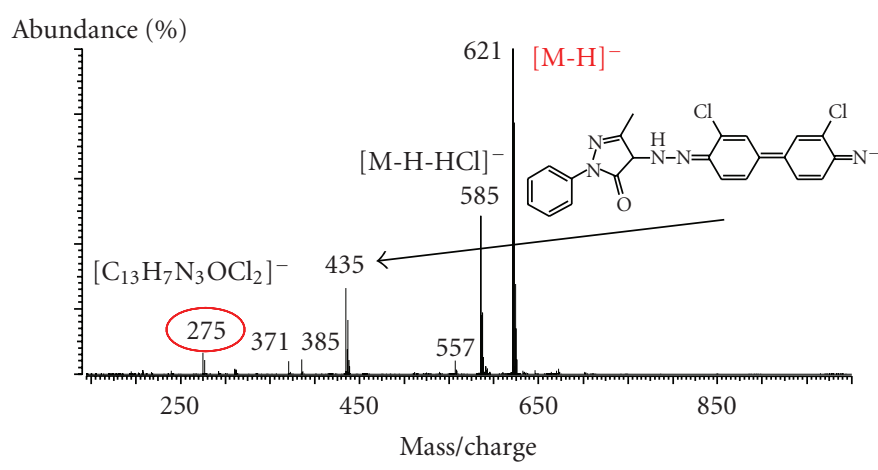

(a)

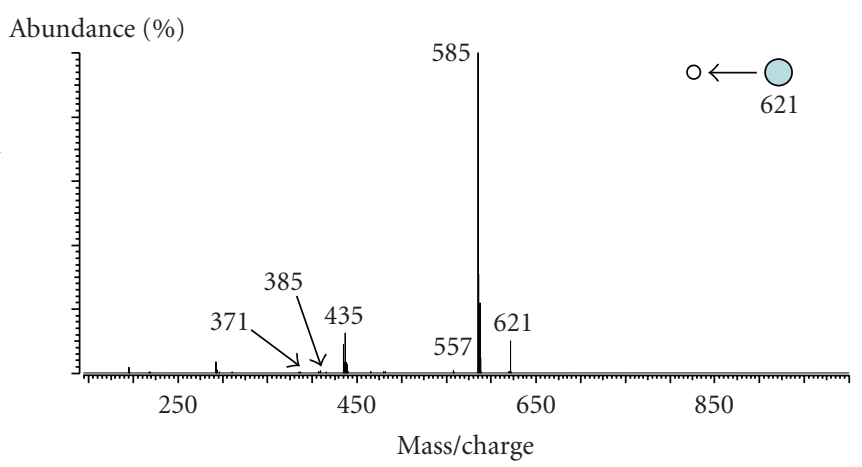

(b)

FIGURE 3: (a) LDI-FTICRMS analysis of standard orange pigment in negative-ion detection mode at the wavelenght of $355 \mathrm{~nm}$ and (b) tandem mass spectrum in SORI-CID mode of $[\mathrm{M}-\mathrm{H}]^{-}$pseudomolecular ion.

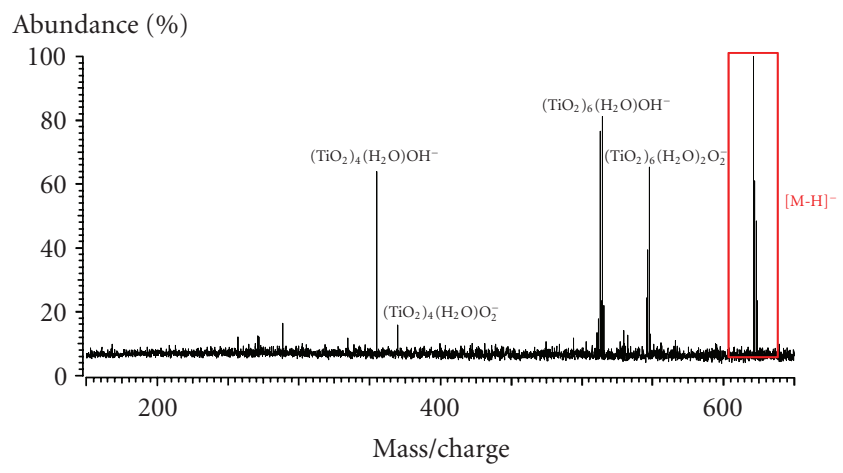

(a)

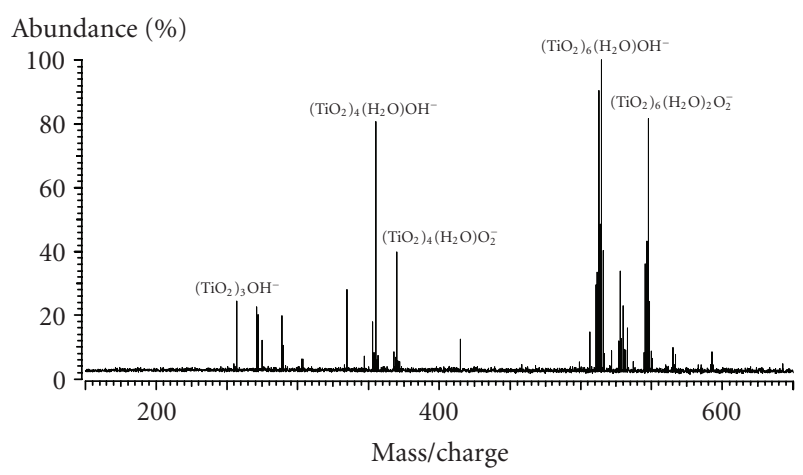

(b)

FIGURE 4: LDI-FTICRMS spectrum of NR-based orange flooring in negative-ion detection mode at the wavelenght of $355 \mathrm{~nm}$ (a) before and (b) after aging.

and 2(b)). Cracks can be observed for the first 75 and $300 \mu \mathrm{m}$ of depth with SBR and NR floorings, respectively. Consequently, it can be argued that aging processes lead only to surface or near surface degradation and that depth degradation is dependant of the polymer (NR or SBR). The distribution of different atoms in the degraded portion of flooring as well as at the interface of altered/nonaltered composite material is investigated by EDX mapping and is reported in Figures 2(c) and $2(\mathrm{~d})$. The more important information is obtained when chlorine atom mapping is considered. Significant differences appear when NR- and SBR-based aged flooring behavior is compared. Aged NR flooring $\mathrm{Cl}$ mapping shows a homogeneous distribution of chlorine atoms whereas aged SBR denotes a higher concentration of $\mathrm{Cl}$ at the surface compared to the bulk. Reader has to keep in mind that two chlorine atoms are present in the orange pigment molecule (see Scheme 1). Due to the fact that chlorine is not present in the structure of other organic and inorganic components of the composite, chlorine is thought to be relevant of pigment or at least of its degradation products. Consequently, it is assumed that aging of SBR induced an enrichment of the surface by the orange pigment.

\section{LDI-FTICRMS measurements}

Prior to perform analysis of SBR and NR floorings, LDIFTICRMS experiments has been conducted on the standard orange pigment to obtain an MS fingerprint of this compound. Its LDI-FTICRMS negative mass spectrum is presented in Figure 3. Different negative ions are detected. More specifically, $\mathrm{m} / \mathrm{z} 621,585,435$, and 275 ions are observed on the mass spectrum. $\mathrm{m} / \mathrm{z} 621$ ion is associated to the $[\mathrm{M}-\mathrm{H}]^{-}$ pseudomolecular ion of orange pigment. $\mathrm{m} / \mathrm{z} 585$ and 435 correspond to fragments of pseudomolecular ion. The first one is thought to be $[\mathrm{M}-\mathrm{H}-\mathrm{HCl}]^{-}$whereas the second one corresponds to the release of a more important moieties of the pigment molecule (see assignment in Figure 3 ).

Figure 4 gathers LDI-FTICRMS spectra of NR flooring before and after aging. The main detected species on the mass spectrum before aging are associated to orange pigment and $\mathrm{TiO}_{2}$ filler. $[\mathrm{M}-\mathrm{H}]^{-}$pseudomolecularion is detected at $\mathrm{m} / \mathrm{z}$ 621. Cluster ion associated to titanium dioxide mainly consists of association of $\mathrm{TiO}_{2}$ and $\mathrm{H}_{2} \mathrm{O}$ building blocks with $\mathrm{OH}^{-}$or $\mathrm{O}_{2}^{-}$charge carriers. After aging, these latter species are the solely detected ions. The $[\mathrm{M}-\mathrm{H}]^{-}$pseudomolecular 
TABLE 1: S/N ratio of detected ions in the LDI-FTICRMS study of SBR and NR flooring samples before and after aging (nd: not detected).

\begin{tabular}{llccc}
\hline & & $\begin{array}{c}\text { Fragment } \\
\mathrm{m} / \mathrm{z} 435\end{array}$ & $\begin{array}{c}{[\mathrm{M}-\mathrm{H}-\mathrm{HCl}]^{-}} \\
\mathrm{m} / \mathrm{z} 585\end{array}$ & $\begin{array}{c}{[\mathrm{M}-\mathrm{H}]^{-}} \\
\mathrm{m} / \mathrm{z} 621\end{array}$ \\
\hline \multirow{2}{*}{ SBR flooring } & Before aging & 125 & 46 & 108 \\
& After aging & 98 & 60 & 250 \\
\hline \multirow{2}{*}{ NR flooring } & Before aging & nd & nd & 25 \\
& After aging & nd & nd & nd \\
\hline
\end{tabular}

ion is not more detected. Similar experiments have been conducted with SBR-based flooring. Results for NR and SBR before and after aging are summarized in Table 1 . In contrast to what it is observed with NR, the aging of SBR flooring does not lead to a decrease of the $[\mathrm{M}-\mathrm{H}]^{-}$signal on the mass spectra but to an increase of its $\mathrm{S} / \mathrm{N}$ (signal/noise) ratio by a factor of 2. Consequently, the huge difference in LDI-FTICRMS behavior for both floorings is the evolution of the $[\mathrm{M}-\mathrm{H}]^{-}$with the aging treatment, which clearly indicates the influence of the polymer matrix on the degradation of the composite material, especially the degradation of the orange pigment.

\section{CONCLUSION}

The LDI-FTICRMS analysis of NR- and SBR-based flooring before aging clearly demonstrates the ability of this technique to detect the orange pigment in composite material by means of the observation of $[\mathrm{M}-\mathrm{H}]^{-}$pseudomolecular ion and also its fragment ions. The LDI-FTICRMS behavior of floorings after aging is highly dependant of the polymer matrice. Indeed, after UV irradiation, the abundance of $[\mathrm{M}-\mathrm{H}]^{-}$ion increases for SBR whereas it dramatically decreases for NR, which means that orange pigment is significantly destroyed at the surface of NR flooring whereas it concentrates at the surface for SBR flooring. This is confirmed by both EDX and UV/Vis spectroscopy. EDX analysis indicates a concentration of chlorine atoms, which is a marker of orange pigment or of its degradation products at the surface of SBR flooring after aging, which is not observed with NR. Moreover, the $\mathrm{UV} / \mathrm{Vis}$ absorption behavior is only slightly modified after aging for SBR flooring whereas NR absorption decreased significantly between $350-600 \mathrm{~nm}$ (pigment absorption wavelengths). As a consequence, it is assumed that both polymer matrices undergo degradation processes, which is confirmed by the broadening of polymer absorption band and the observed pseudo- "red shift" formation of unsaturation and incorporation of oxygen atoms. Degradation products and especially peroxides and hydroperoxides radicals greatly affect the behavior of the organic pigment. For NR, these species are thought to interact with the orange pigment, which leads to its destruction. In contrast, the radicals formed during SBR flooring aging appear to be inefficient to degrade the pigment. Nevertheless, the partial destruction of SBR polymer matrix allows pigment to migrate and concentrate at the surface, leading to a darker material. The modification of the absorption behavior of the polymer (see in Figure 1) seems to be indicative of unsaturations formation, which only could be obtained by the release of hydrogen radical for SBR and hydrogen and methyl ones for NR. The understanding of the interaction of these radicals with the orange appears consequently to be the key point to better understand the aging processes.

\section{REFERENCES}

[1] K. A. M. dos Santos, P. A. Z. Suarez, and J. C. Rubim, "Photodegradation of synthetic and natural polyisoprenes at specific UV radiations," Polymer Degradation and Stability, vol. 90, no. 1, pp. 34-43, 2005.

[2] D. Ruch, C. Boes, R. Zimmer, J. F. Muller, and H.-N. Migeon, "Quantitative analysis of styrene butadiene copolymers using SSIMS and LA-FTICRMS," Applied Surface Science, vol. 203-204, pp. 566-570, 2003.

[3] L. P. Real, J.-L. Gardette, and A. Pereira Rocha, "Artificial simulated and natural weathering of poly(vinyl chloride) for outdoor applications: the influence of water in the changes of properties," Polymer Degradation and Stability, vol. 88, no. 3, pp. 357-362, 2005.

[4] T. Dienes, S. J. Pastor, S. Schürch, et al., "Fourier transform mass spectrometry-advancing years (1992-mid. 1996)," Mass Spectrometry Reviews, vol. 15, no. 3, pp. 163-211, 1996.

[5] A. G. Marshall, C. L. Hendrickson, and G. S. Jackson, "Fourier transform ion cyclotron resonance mass spectrometry: a primer," Mass Spectrometry Reviews, vol. 17, no. 1, pp. $1-35,1998$.

[6] A. G. Marshall and C. L. Hendrickson, "Fourier transform ion cyclotron resonance detection: principles and experimental configurations," International Journal of Mass Spectrometry, vol. 215, no. 1-3, pp. 59-75, 2002. 


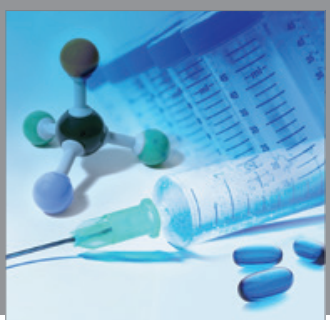

International Journal of

Medicinal Chemistry

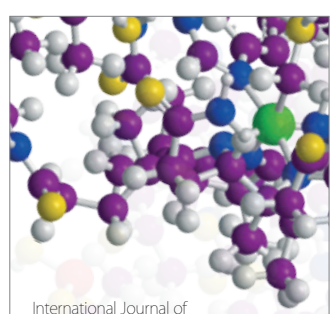

Carbohydrate Chemistry

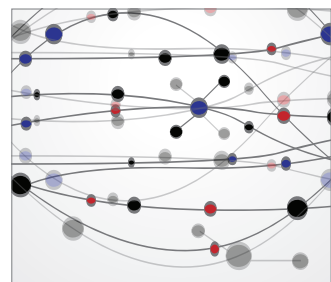

The Scientific World Journal
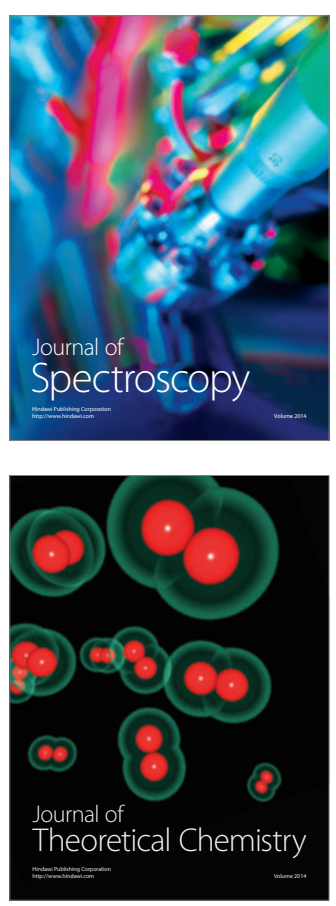
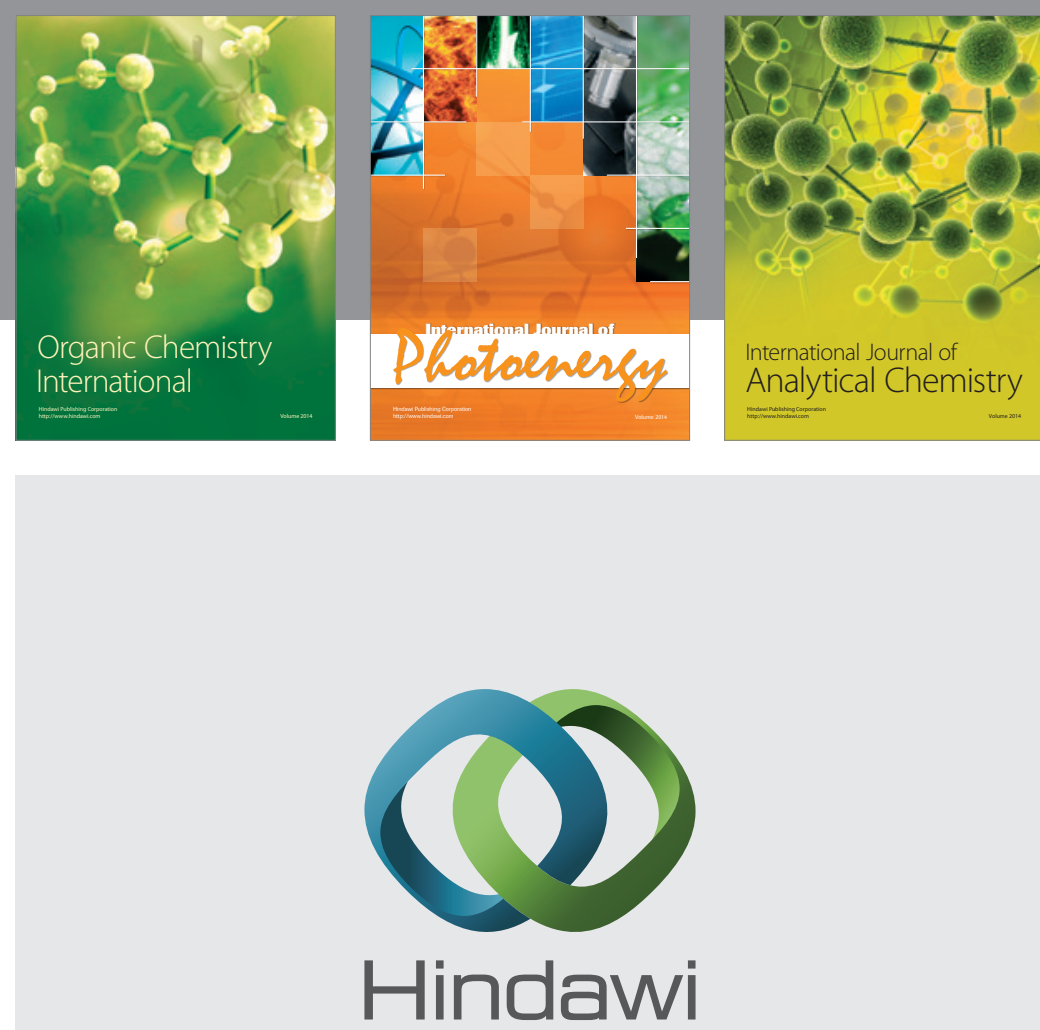

Submit your manuscripts at

http://www.hindawi.com
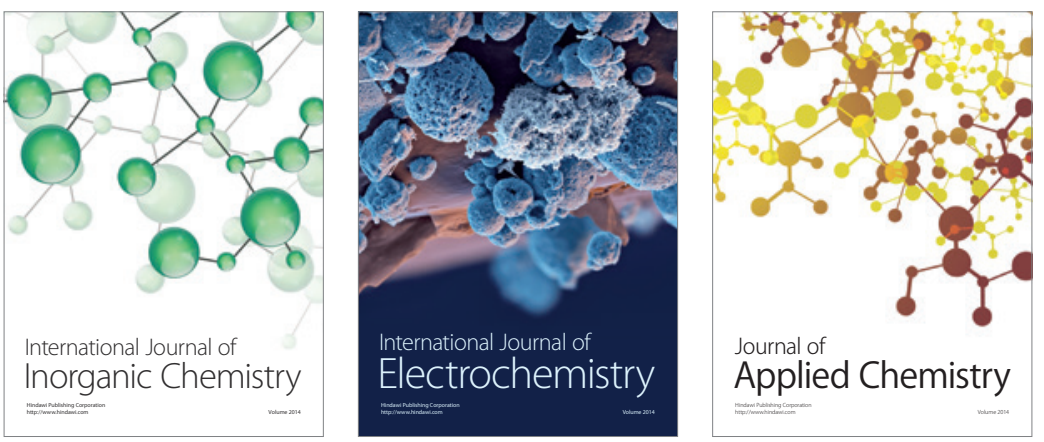

Journal of

Applied Chemistry
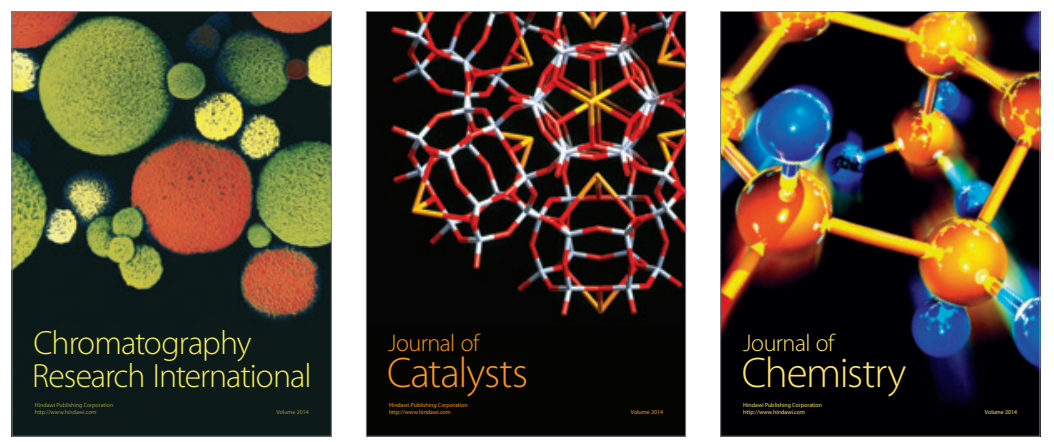
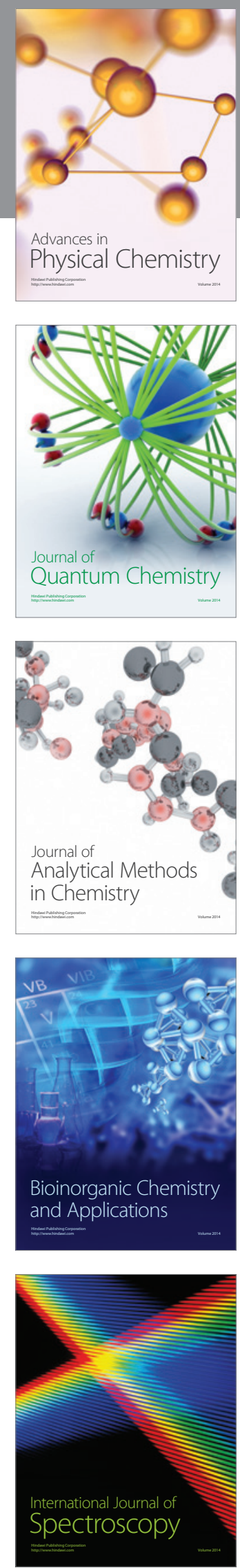